\title{
Ways forward for resilience thinking: lessons from the field for those exploring social-ecological systems in agriculture and natural resource management
}

\author{
$\underline{\text { Katrina Sinclair }}^{1,2}, \underline{\text { Andrea Rawluk }}^{3}, \underline{\text { Saideepa Kumar }}^{4}{\text { and }{\text { Allan } \text { Curtis }^{2}}^{2}}^{2}$
}

\begin{abstract}
Resilience thinking appears to offer a holistic approach that can be used by social researchers to interpret past and contemporary conditions and identify possible futures for social-ecological systems (SES). Resilience thinking is shaping contemporary environmental policy and its implementation in Australia, Europe, and North America. At the same time, social researchers have raised concerns about the limitations of resilience thinking, particularly in its handling of human agency, power relationships, social thresholds, and the social construction of SES definitions. We argue for a reflexive turn in resilience thinking as a way to address these concerns. We draw on lessons from three Australian case studies where a reflexive application of resilience thinking generated insights for research and practice. We propose six areas for reflexive inquiry: (1) focal scale and level, (2) SES definition, (3) narratives of change, (4) processes of knowledge production, (5) social transition trajectories, and (6) social thresholds. In so doing, the assumptions of resilience thinking are politicized and problematized, which improves its theoretical analytical utility, and in practice generates new insights into social processes. Reflexivity offers opportunity for greater cross-disciplinary dialogue between resilience thinking and the social sciences, while allowing methodologies with differing ontologies and epistemologies to be applied in a complementary manner.
\end{abstract}

Key Words: agriculture; limitations; natural resource management; reflexivity; resilience framework; social-ecological systems

\section{INTRODUCTION}

Agriculture and natural resource management agencies in Australia and overseas, including Europe and North America, have embraced resilience thinking, and the key ideas of resilience thinking have influenced the understanding and management of ecological systems. Examples include studies of the Great Barrier Reef (Australia) and the Kristianstads Vattenrike Biosphere Reserve (Sweden). The principles of resilience thinking are also shaping discourse in natural resource management planning. For example, resilience principles guide the management of landscapes at risk of bushfire in the Australian state of Victoria and watershed plans in the state of New South Wales.

Resilience thinking is a conceptual framework that encapsulates a multifaceted approach to describing and analyzing change in social-ecological systems (SES) as integrated social and environment subsystems (Folke et al. 2010). The focus of resilience thinking is on the system as a whole, and emphasizes the interrelatedness of individual components and the processes operating within a system (Welsh 2014). Resilience thinking provides an alternative narrative to the conventional idea of resilience based on equilibrium dynamics and predictability of change with an implied understanding that change should be resisted to maintain stability (Gunderson and Holling 2002, Folke 2016).

Early resilience research focused on ecological resilience as a way of understanding the effect of a disturbance on an ecosystem's adaptability and persistence (Folke 2006). Over time, resilience research shifted emphasis to SES resilience with a focus on understanding SES as complex adaptive systems that incorporate the ideas of nonlinear dynamics, thresholds and tipping points, feedback loops, self-organization, and multiple stable states (Hahn and Nykvist 2017). Contemporary resilience thinking is focused on resilience as a measure of persistence, adaptability (human actions taken to sustain the existing system), and transformability (human actions taken to create or enable a fundamentally new system), and the dynamic interplay between these three aspects in response to changing circumstances (Folke et al. 2010). Deliberate transformation involves the intentional breaking down of specific resilience of the old system (by restructuring a system's components and relationships) and building resilience in the new system (O'Brien 2012, Folke 2016).

Resilience thinking has considerable intuitive appeal for social researchers in that it acknowledges that contemporary environments are shaped by people, and the analytical framework captures the intertwined nature of people and environments (Gunderson and Holling 2002, Folke 2016). A key concept proposed by resilience-thinking scholars for describing change is the adaptive cycle, which outlines a sequence of four development phases that most systems undergo: exploitation (growth), conservation (accumulation), collapse (restructuring), and reorganization (renewal) (Gunderson and Holling 2002). The adaptive cycle has been used as a heuristic for resilience assessments (Allison and Hobbs 2004, Lyon and Parkins 2013), for exploring change in resilience in SES over time (Walker et al 2009, Lockwood et al. 2014), for conceptualizing changing power dynamics (Pelling and Manuel-Navarrete 2011), and for identifying social traps (Fath et al. 2015). Indeed, resilience thinking has served as a boundary object across disciplines and practices (Brand and Jax 2007), for example, by introducing a radical theory of change from complex systems sciences to the fields of agriculture and natural resource management (Walker and Salt 2006). It broadens the social domain from merely analyzing human-nature interactions at one level to consider feedback loops and thresholds across multiple levels (Folke et al.

${ }^{1}$ NSW Department of Primary Industries, ${ }^{2}$ Graham Centre for Agricultural Innovation, Charles Sturt University, Wagga Wagga, Australia, ${ }^{3}$ School of Ecosystem and Forest Sciences, University of Melbourne, ${ }^{4}$ School of Environmental Sciences, Charles Sturt University 
2010). In addition, by adopting the concept of linked SES, social dimensions are increasingly considered in theories of ecosystem change, and in natural resource management practice (Brown 2014).

At the same time, social researchers have outlined particular limitations of the current conceptualization of resilience thinking from the perspective of contemporary social theory (Davidson 2010, 2013, Coté and Nightingale 2012) and, subsequently, ways in which resilience thinking can be developed. They have contested the application of ecological concepts to the functionalist study of humans and social dynamics and argued for a closer integration with broader social theory (Hatt 2013, Brown 2014). Common critiques of resilience thinking include inadequate recognition of human agency and heterogeneous perspectives, lack of emphasis on the role of power relationships and dynamics, inability to identify social thresholds in advance, and little reflection on the social construction of system definitions (described in the following section). Differences in disciplinary orientations and focus between ecology and social sciences limit the extent of integrating social theories into resilience thinking.

We build on the emerging and closer integration of the social sciences with resilience thinking to argue for a reflexive turn as a way to address the critiques put forth by social researchers. We use lessons from three Australian case studies to illustrate the insights to be gained from a reflexive application of resilience thinking. As a concept, reflexivity has gained currency in disciplines such as sociology, psychology, anthropology, education, management, and organizational research, with varying uses of the term (see Lynch [2000] for an inventory of meanings ascribed to the term). We use the term "reflexivity" to mean embracing of "subjective understandings of reality as a basis for thinking more critically about the impact of our assumptions, values, and actions on others" (Cunliffe 2004:407). Thus, a reflexive methodology would rely on two orientations: the recognition of difference and diversity in interpretations of reality (a social constructivist lens), and critical reflection on foundational assumptions and structures of power that shape constructions of reality (a critical theoretic lens). A reflexive inquiry would not replace a more conventional application of resilience thinking as a descriptive theory or an analytical framework, but would serve as a complementary exercise that exposes each of resilience thinking's key assumptions to selfreflection and opens up avenues for alternative paradigms and marginalized interpretations to be considered.

In the sections that follow, we summarize the common critiques of resilience thinking put forth by social researchers and then present an outline of the three case studies, their use of resilience thinking, and the insights gained in each case. Drawing on our experience in the case studies and from suggestions put forth by others (Fabinyi et al. 2014, Ingalls and Stedman 2016), we propose six areas for the conceptual growth in resilience thinking through reflexive inquiry.

\section{Common critiques of resilience thinking by social researchers}

The first critique is that resilience thinking needs to expand the conceptualization of social dynamics (Brown 2014), including the heterogeneity of perspectives that exist (Rawluk and Godber 2011, Coté and Nightingale 2012) and the extent of human agency
(Davidson 2010). Social researchers have argued that resilience thinking studies that have examined local or community resilience have typified "community" and "local" as homogenous entities characterized by common interests (Fabinyi et al. 2014). People have the capacity to reflect on the past and imagine the future, to improvise, to anticipate change, and to choose how they will respond: to act or not (Davidson 2010, Davoudi 2012). As a consequence, there is likely to be substantial variability in the actions people choose to take when navigating change. Bristow and Healy (2014) point out that by using ingenuity and foresight, people may not respond according to the anticipated phases of the adaptive cycle. Thus, human agency contributes to the complexity and unpredictability of change processes and the subsequent outcomes (Brown and Westaway 2011, Davidson 2013).

The second critique is that resilience thinking needs to emphasize the importance of power relationships in the change process, including the potential for negative outcomes for the less powerful (Kuhlicke 2013). For example, resilience thinking acknowledges the role of power relationships in institutional processes (Tompkins and Adger 2004), but there is a very limited examination of the expression of power through knowledge and discourse. Even though uncertainty and plurality of knowledge are widely recognized in resilience thinking, the focus is generally on the content of knowledge rather than the process of knowledge production within a context (Coté and Nightingale 2012). The role of culture, class, and other power structures in the production, legitimization, and codification of knowledge needs to be more thoroughly examined and questioned. MacKinnon and Derickson (2013) and Brown (2014) go so far as to suggest that the currently limited accounting for power dynamics in resilience thinking tends to privilege existing structures and modes of governance.

The third critique is that resilience thinking needs to provide more guidance on identifying when and where key social variables may reach thresholds that provide a "window of opportunity" or a trigger to drive system change (Walker and Salt 2006). To an extent, Walker and Salt (2012:75) acknowledge that "thresholds in social and economic domains might be harder to identify" than those in ecological domains. In ecology, thresholds are commonly described in terms of an observable critical limit such as a nutrient load that affects ecological function. However, in sociology, thresholds in important variables, such as the erosion of trust, are not readily identified, and individual judgments about the nature of such relationships will vary (Christensen and Krogman 2012).

The fourth critique we highlight is that resilience thinking gives the impression that SES are ontological material entities that can be identified by researchers or jointly with some stakeholders (Kirchhoff et al. 2010, Brown 2014). In academic and policy discourse based on resilience thinking, there is little reflection on the social construction of a system definition or the plurality of system definitions (Welsh 2014). In failing to question the ontological nature of an SES, the normative implications of a system definition and of "resilience" as a property of that system are obscured (MacKinnon and Derickson 2013).

\section{INSIGHTS FROM THREE CASE STUDIES}

In this section, we draw on insights from three case studies in Australia where resilience thinking was used to describe, analyze, 
Table 1. A summary of the three case studies.

\begin{tabular}{|c|c|c|}
\hline $\begin{array}{l}\text { Case study 1: Deregulation of the Subtropical } \\
\text { Dairy industry, northeastern Australia (Sinclair } \\
\text { 2014) }\end{array}$ & $\begin{array}{l}\text { Case study 2: Landscape change in the Ovens } \\
\text { catchment, Victoria, Australia (Rawluk 2015) }\end{array}$ & $\begin{array}{l}\text { Case study 3: Environmental water in the } \\
\text { Murray-Darling Basin, Australia (Kumar 2016) }\end{array}$ \\
\hline \multicolumn{3}{|l|}{$\overline{\text { Context }}$} \\
\hline $\begin{array}{l}\text { In } 2000 \text {, the Australian dairy market was } \\
\text { deregulated to establish an open milk market. } \\
\text { Deregulation exposed the family-owned high- } \\
\text { cost milk production systems and the fresh } \\
\text { milk supply chain to a highly competitive and } \\
\text { volatile market. }\end{array}$ & $\begin{array}{l}\text { In the Ovens catchment, a dominant and } \\
\text { influential discourse was shaping rural } \\
\text { decision-making by governments and other } \\
\text { stakeholders in transitioning the catchment } \\
\text { from a post-tobacco and dryland agricultural } \\
\text { landscape to a highly irrigated food bowl. }\end{array}$ & $\begin{array}{l}\text { Water management discourse in the Murray- } \\
\text { Darling Basin is dominated by the tension } \\
\text { between the productive agricultural economy } \\
\text { and the attendant degradation of riverine } \\
\text { ecosystems. Environmental water is used to } \\
\text { improve "river health," which is conceived as a } \\
\text { precarious balance between the socioeconomic } \\
\text { and the ecological values held for water. }\end{array}$ \\
\hline \multicolumn{3}{|l|}{ Study Approach } \\
\hline $\begin{array}{l}\text { Analysis of stakeholder interview data to } \\
\text { explore the value of resilience thinking as a } \\
\text { lens to understand the processes and outcomes } \\
\text { of change in the Subtropical Dairy industry } \\
\text { following deregulation as a case of deliberate } \\
\text { transformative change. }\end{array}$ & $\begin{array}{l}\text { Analysis of interview data, historical } \\
\text { documents, national census, and other } \\
\text { secondary sources to identify different } \\
\text { narratives and a bricolage approach used to } \\
\text { identify landscape transition. }\end{array}$ & $\begin{array}{l}\text { Analysis of interview data and policy } \\
\text { documents to examine definitions of a river } \\
\text { social-ecological system. Cognitive mapping } \\
\text { used to identify boundary judgments, while } \\
\text { boundary critique used for critical examination. }\end{array}$ \\
\hline \multicolumn{3}{|l|}{ Application of Resilience Thinking } \\
\hline $\begin{array}{l}\text { Applied resilience thinking concepts to } \\
\text { describe, analyze, and interpret the nature and } \\
\text { extent of change associated with market } \\
\text { deregulation in the Subtropical Dairy industry. }\end{array}$ & $\begin{array}{l}\text { The adaptive cycle was used as a comparative } \\
\text { tool to expose multiple local narratives of the } \\
\text { state of the landscape and to reconcile the } \\
\text { current state of the landscape. }\end{array}$ & $\begin{array}{l}\text { Identified and explored the implications of the } \\
\text { differing definitions of the river social- } \\
\text { ecological system in policy and planning } \\
\text { documents, scientific studies, and stakeholder } \\
\text { perceptions. }\end{array}$ \\
\hline \multicolumn{3}{|l|}{ Usefulness of Resilience Thinking } \\
\hline $\begin{array}{l}\text { The adaptive cycle provided a useful organizing } \\
\text { framework for describing change over time. } \\
\text { With hindsight, key controlling variables could } \\
\text { be identified and judgments could be made } \\
\text { about when critical thresholds were reached. } \\
\text { Nonlinearity was reflected in the periods of } \\
\text { chaos and instability experienced by the } \\
\text { industry. A shift to a new regime is suggested, } \\
\text { with the new state being more or less desirable } \\
\text { for different stakeholders. }\end{array}$ & $\begin{array}{l}\text { The adaptive cycle provided a useful organizing } \\
\text { framework to compare the multiple narratives } \\
\text { of change. It also enabled the observation that } \\
\text { different stakeholder groups actually perceived } \\
\text { the social-ecological system to be in different } \\
\text { phases of the cycle, from conservation and } \\
\text { precollapse to reorganization and early } \\
\text { exploitation. }\end{array}$ & $\begin{array}{l}\text { Social-ecological system was a useful construct } \\
\text { to conceptualize river catchments in the } \\
\text { Murray-Darling Basin. Resilience thinking } \\
\text { adequately draws attention to the complex } \\
\text { interplay between social and ecological } \\
\text { phenomena across multiple scales. } \\
\text { Unpredictability of system responses and } \\
\text { uncertainty of knowledge are acknowledged in } \\
\text { policy discourse. }\end{array}$ \\
\hline Limitations of Resilience Thinking Identified & & \\
\hline $\begin{array}{l}\text { Resilience thinking does not adequately } \\
\text { emphasize the role of human agency in } \\
\text { anticipating or responding to change, or the } \\
\text { role of power and power relations. Resilience } \\
\text { thinking offers no advice on how to identify } \\
\text { social thresholds in advance. }\end{array}$ & $\begin{array}{l}\text { Multiple narratives of change are not } \\
\text { examined. The phase sequences of the adaptive } \\
\text { cycle did not reflect the researcher's } \\
\text { interpretation of the change process. }\end{array}$ & $\begin{array}{l}\text { Resilience thinking does not prompt reflection } \\
\text { on the socially constructed nature of social- } \\
\text { ecological system definitions. There is little } \\
\text { emphasis on knowledge generation processes or } \\
\text { their role in shaping discourse. }\end{array}$ \\
\hline
\end{tabular}

and interpret change in agricultural systems. The first case study (Sinclair 2014) explored the extent that market deregulation of the Australian dairy industry deliberately transformed the Subtropical Dairy industry. The second study (Rawluk 2015) exposed and reconciled contradictory stakeholder narratives of a rural landscape in transition, the Ovens Valley catchment. The third study (Kumar 2016) evaluated the policy of allocating and releasing water for the environment (i.e., water set aside to improve "river health") in the Murray-Darling Basin. The three case studies had very different objectives, but in each case, a reflection on the limitations of resilience thinking produced valuable insights. A synthesis of the three case studies is provided in Table 1 , followed by a brief discussion on the key lessons from each study.

\section{Case study 1: Deregulation of the Subtropical Dairy industry} Sinclair (2014) found that most resilience thinking concepts were useful in describing, analyzing, and interpreting the nature and extent of change that suggested the deliberate exposure of the Subtropical Dairy industry to a deregulated fresh milk market was transformative. Indeed, the Subtropical Dairy industry could be described as displaying general resilience after a period of chaos and instability that followed deregulation. However, when analyses were centered on the resilience of individual players or networks of actors, different stories about the responses to, and insights about, the powerful role of the retail sector emerged.

Although governments strongly influenced the change process, the period immediately after deregulation saw supermarkets exert a greater influence on emergent outcomes. For example, supermarkets took immediate steps to increase the market share 
held by their private labeled milk products, which undercut the branded milk price placed on their shelves. These price cuts were passed down the supply chain, which squeezed the margins of milk processors and producers. In response, at the farm level, some producers upgraded farm infrastructure, adopted new practices, and attained new skills to enable them to increase production and lower their production costs. Many others could not cope with the new conditions and left the industry. Social networks degraded and a different culture emerged within the industry, with an emphasis on competition, efficiency, and profit margins. As others (Davidson 2013) have pointed out, human agency, in anticipation or in response to change, can introduce unexpected complexity and variability in a social system. By focusing on the individual players in the dairy industry, insights were revealed about the change in social relationships between stakeholders as they sought to take advantage of the new environment. Following deregulation, supermarkets emerged as the most powerful player in the supply chain, which altered structural relationships between all players. Clearly, there were winners and losers. This raises the important, yet neglected, question of "resilience of what, for whom and at what cost to others" (Coté and Nightingale 2012, Strunz 2012, Brown 2014).

When applying resilience thinking as a lens, one of the key social variables was identified as the degradation of social capital in terms of both structural (related to the breakdown in producers' social networks) and cognitive (related to the breakdown in trust between the producer and milk processor) elements. However, change in social relations at the farm scale occurred much more slowly than changes in farm structure and work practices, and thresholds appeared to be different for each actor, which made it difficult to discern when a social threshold had been exceeded. As Nelson et al. (2007) and Chritensen and Krogman (2012) have both noted, thresholds of key variables are difficult to predict in complex SES and are often obvious only once a system is changing or has been changed. Nonetheless, recognizing that such unpredictable social variables could lead to regime shifts, adopting strategies that provide opportunities to rebuild social capital, such as providing producer social gatherings, and opportunities for the retailers and milk processors to offer fair and reasonable milk supply contracts could, to an extent, reverse the loss of social capital.

\section{Case study 2: Landscape change in the Ovens catchment}

Rawluk (2015) found that the adaptive cycle was useful in revealing and recognizing three contradictory stakeholder narratives of landscape change since the 1950s in the Ovens catchment. Applying the adaptive cycle in this manner highlighted the dominance of a single narrative that enabled farmers to exercise power over decisions about land use and resource access. The farmer narrative was that of a productivist agricultural landscape approaching collapse, and the best solution to protect the regional economy was to promote the development of a highly irrigated food bowl.

This farmer narrative was shaping the response of governments with funds allocated to trial "profitable" agricultural enterprises and to limiting the subdivision of rural land to protect the future of agriculture. However, using the adaptive cycle, Rawluk (2015) found a contradictory narrative advanced by local politicians to be a more credible reflection of the actual state of the Ovens catchment that was at a later phase. The politicians' narrative suggested that the landscape had transitioned to a multifunctional landscape, where nonagricultural values, including amenity and environmental values, were driving property ownership, land use and management, and the structure of industry and employment. In recognizing the existence of multiple and competing narratives of change and then critically examining the narratives, the study illustrated how power was expressed through discourse, with social memory playing a key role (Rawluk and Curtis 2017).

This study is consistent with the findings of other researchers that indicated that social transition trajectories may not follow the phased sequence of the adaptive cycle (Pelling and ManuelNavarrete 2011, Fath et al. 2015). Together, this research suggests that there can be multiple pathways as an SES reorganizes. In the Ovens case study, the catchment reorganized as a result of substantial amenity migration and the growth service industries, including tourism. There was no evidence that this reorganization involved a more "exploitative" regime. Indeed, it is possible that the new economy involves less exploitation of the natural resource base. Recognizing this possibility, Rawluk and Curtis (2016) highlighted the importance of acknowledging the potential for multiple trajectories of change.

\section{Case study 3: Environmental water in the Murray-Darling Basin}

In the third case study, Kumar (2016) found in examining the foundational policy assumptions of allocating and managing environmental water in the Murray-Darling Basin that many of the policy and planning documents recognize catchments in the Murray-Darling Basin as SES. Furthermore, the principles of resilience thinking are recognized in policy and academic discourse related to environmental water. The concept of SES was a useful construct for conceptualizing river catchments and would have provided additional insight if more consideration was given to either the socially constructed nature of an SES definition or the examination of processes that generate the knowledge that underpins the definition of an SES.

Boundary critique (Ulrich 1983) was used to identify and compare different conceptualizations (or boundary judgments) of the river SES. The analysis of boundary judgments revealed that the Murray-Darling Basin River SES is defined and interpreted differently in various institutional arrangements and scientific studies, and by stakeholders. Boundary judgments on the scope of the SES differed according to the purpose at hand, the interests of the people involved, and the knowledge that was available or considered to be relevant. It was found that the demands for institutional certainty and accountability favored narrow boundaries for the SES. The river SES was narrowly focused on the economic interests of irrigation and the needs of riverine ecosystems. Underrepresented interests, including Aboriginal cultural values, and recreational and aesthetic uses of rivers, were marginalized.

Further, research to support the management of environmental water continues to be directed at improving the predictability of key variables (which are also measurable) without questioning if those variables would indeed be important objectives if the SES was conceived in a different manner. When boundary assumptions of knowledge claims about ecological responses to river flows were examined, it was found that they were not clearly established, yet these claims are used to design and fund research 
and monitoring programs. While policy discourse in the MurrayDarling Basin has clearly embraced resilience thinking, operational procedures continue to reinforce entrenched models and institutions. These problems cannot be attributed to resilience thinking in and of itself; however, it can be said that by drawing explicit attention to the socially constructed nature of SES and to the processes of knowledge generation, resilience thinking can promote critical reflection on the implications of defining an SES in a specific manner.

\section{WAYS FORWARD FOR RESILIENCE THINKING: REFLEXIVE APPLICATION}

Resilience thinking was found to be a useful analytical framework for broadly understanding the nature and extent of change in the case studies we described, but significant limitations in the ability of resilience thinking to explain social processes were also identified. Our view is that these limitations are, in fact, significant and optimistic areas for growth and development, not simply problems with the theory and application of resilience thinking. Resilience thinking needs to prompt reflection on its assumptions about agency, power, knowledge, and scale. The utility of resilience thinking in dealing with the realities of humanenvironmental relations will be enhanced if there is greater acknowledgement of the social and political struggles that influence change in SES (Fabinyi et al. 2014, Sinclair et al. 2014).

A common lesson learned from the three case studies was that a reflexive application of resilience thinking generates new and useful insights for research and management. Reflexivity in resilience thinking would mean that both resilience thinking theorists and practitioners examine the implications of their epistemology on outcomes for different people and processes, and reflect on the broader social and political struggles that privilege a discourse or social group over others. A closer examination of key concepts and assumptions of resilience thinking in each context can expose sources of contingency and uncertainty, which are otherwise hidden. A reflexive approach allows for methodologies with differing ontologies and epistemologies to be applied in a complementary manner by using their respective perspectives to provide meaningful contrasts and enable critical reflection. Not only would such an approach help address some of the long-standing critiques of resilience thinking, it would also enhance resilience thinking's function as a boundary object for constructive dialogue across disciplines.

The application of a reflexive approach is not without its own challenges or criticisms. As Lynch (2000) points out, those who do not share a commitment to social constructivism would argue that reflexivity leads to infinite regress, and ultimately, becomes self-refuting. We contend that infinite regress is an issue only if we seek to develop an overarching theory of resilience thinking that subsumes all its critiques. Instead, we contend that reflexivity is necessarily contextual and related to practice. That is, it is with reference to a specific SES, a specific purpose, and specific social and political processes that the resilience thinking framework can be examined. Furthermore, reflexive analysis does not guarantee the generation of critical insights or the achievement of emancipatory objectives. As Lynch (2000:36) puts it, "what reflexivity does, what it threatens to expose, what it reveals and who it empowers depends upon who does it and how they go about it." Nonetheless, we propose that the theory of resilience thinking could unsettle some of its assumptions so that researchers and practitioners are prompted to apply resilience thinking in a reflexive manner.

In the following sections, we propose six areas (or "problematics") for reflexive inquiry to support the refinement and growth of resilience thinking: (1) focal scale and level, (2) SES definition, (3) narratives of change, (4) processes of knowledge production, (5) social transition trajectories, and (6) social thresholds. The term "problematic" is used not to imply error in conceptualization, but to identify the concept as a candidate for deconstruction. For each problematic, we propose some questions that could help uncover the role of human agency, power dynamics, and trade-offs. We bring together our experience in the three case studies and suggestions put forth by others to outline how resilience thinking can be applied reflexively for research, using methodologies inspired by political ecology, critical systems thinking, and bricolage (Kincheloe 2005).

\section{Problematic of focal scale and level}

The minimal emphasis on human agency in resilience thinking could be attributed to the organizing scale that is typically adopted in resilience thinking: the SES. Resilience thinking assessments tend to focus on local or regional systems; they rarely analyze global processes that structure change in local systems or delve into lower levels, such as individual actors or networks of actors within systems (Fabinyi et al. 2014). Davidson et al. (2016) suggest that diverse interests and perspectives of actors within communities must be foregrounded in research to adequately consider the role of agency. As seen in the first case study on the Subtropical Dairy industry, when the focal scale was individual dairy producers, the role of human agency and power relationships was highlighted. There is also growing recognition that narratives of consensus or win-win outcomes are rarely actualized; the focus of resilience thinking could, therefore, shift to negotiations of trade-offs between competing goals and perspectives (Coulthard 2012).

To undertake a reflexive inquiry on the choice of scale in resilience thinking assessments, one must recognize that scales are social constructions, which are neither given nor politically neutral (Ingalls and Stedman 2016). A reflexive inquiry into the politics of scale could ask, who is involved in selecting the focal scale; who are the winners and losers as a consequence of the chosen scale; what are the implications of selecting an alternative scale?

\section{Problematic of the social-ecological system definition}

Being firmly rooted in systems thinking, resilience thinking studies tend to focus on a "system," be it an ecosystem or an SES, and treat the system as a given ontological entity (Welsh 2014). Resilience thinking theories do not explicitly recognize that the system is a social construct that demands transparency and critical examination. Scholars of critical systems thinking(Ulrich 1983, Midgley 2000) have repeatedly warned that the way a system is defined (or bounded) has significant implications for the design and effectiveness of interventions. They urge systems thinkers to problematize boundary judgments, drawing attention to the practical implications of what is included and excluded from a system definition. The way a system is defined also determines the values and knowledge that are considered relevant (Ulrich 1983). The third case study revealed that the narrow institutional conceptions of the Murray-Darling Basin SES did not represent 
the diverse perspectives of many stakeholders, yet they were seen to drive the selection of targets and the demand for scientific studies to legitimize those selected targets. These insights were useful in questioning the rationality and normative commitments of the dominant discourse of managing environmental water in the Murray-Darling Basin.

A reflexive examination of SES definitions could proceed by asking, what is the purpose of defining a system in a specific way; whose interests and views are privileged or marginalized by the adopted system definition; what values and knowledge become relevant if the system definition is altered; who controls access to resources required for achieving the purpose of the system?

\section{Problematic of narratives of change}

Resilience thinking researchers and practitioners should expect that there will be multiple interpretations of change in a system. As it stands, resilience thinking provides little guidance about how to identify or reconcile multiple and potentially competing narratives of landscape change. Inspired by the work of Foucault, researchers who have adopted political ecology methods have been able to trace the genealogy of environmental narratives and expose the power relationships supported by them (Fabinyi et al. 2014, Ingalls and Stedman 2016). Operating within a reflexive approach, the second case study provides an example of using the adaptive cycle to reveal multiple interpretations of the state of an SES and then challenge a dominant narrative of landscape change.

Questions to guide a critical discursive examination include the following: Are there alternative narratives of change in the SES? What are the reasons for data asymmetries between different narratives? How do alternative narratives affect the distribution of costs and benefits in the system? Would an alternative narrative have implications for governance of an SES, and how would these be managed?

\section{Problematic of knowledge production}

Whereas resilience thinking studies focus on the content of knowledge to aid decision-making, political ecology focuses on the context and process of knowledge production which frames the scope of action (Coté and Nightingale 2012). Interrogation of the politics of knowledge generation can illuminate the role of power imbalances in shaping rationalities. This is demonstrated in the use of boundary critique in the third case study to examine boundary assumptions of knowledge claims that are used in support of planning and monitoring environmental water in a river catchment.

Questions that are relevant to such an interrogation include the following: What was the context (cultural, worldview, purpose, scale) in which the knowledge was generated? What were the data and assumptions involved in producing the knowledge? Who defines the criteria for legitimization of knowledge claims?

\section{Problematic of social transition trajectories}

Social researchers have suggested that following a period of reorganization, multiple SES pathways can emerge that may be more or less exploitative (Fath et al. 2015, Rawluk and Curtis 2016). We reiterate the opportunity to use the adaptive cycle to explore this complexity in greater depth, for example, to reveal the expression of power through discourse (second case study), to identify pathologies and social traps (Fath et al. 2015), or to explore the implications of social transitions on power dynamics (Pelling and Manuel-Navarrete 2011).

How can the adaptive cycle accommodate multiple postreorganization states in social-ecological systems? One way forward is to explicitly acknowledge the potential for multiple trajectories. We suggest it is also critical to move beyond a narrow consideration of ecological impacts and explore the possible social and economic outcomes of reorganization. Perhaps this phase should simply be labeled "post-reorganization trajectories." Questions relevant to such a phase might include the following: What are the possible ecological, economic, and social impacts of reorganization? How will these trends impact different actors?

\section{Problematic of identifying the location of social thresholds}

Thresholds of key social variables are difficult to detect in complex SES, particularly when the changes in social variables are not immediate or obvious. For example, Sinclair et al. (2014) identified that the stock of social capital (a key variable) had been gradually degraded by the breakdown in social relations between dairy producers in place-based communities. They concluded, however, that it was impossible to determine when the extent of these relationships had been sufficiently altered that a threshold had been exceeded.

It seems that social researchers are able to look back to identify key social variables. The challenge is being able to discern when the threshold of a social variable is crossed over. Are social thresholds an aggregation of individual changes? Does a cultural change follow the crossing of a social threshold? We are aware of at least one example where efforts are being made to address that challenge. Groth and Curtis (2017) have suggested that the extent that rural landholders hold farmer occupational identity is a critical variable that can be used to indicate changes in occupance modes (i.e., from productivist modes to those associated with other values) associated with the multifunctional rural transition (Holmes 2006). It is the view of Groth and Curtis (2017) that through studies in areas where such a transition has occurred, it will be possible to identify thresholds in the proportion of rural landholders who identify as farmers by occupation. This could then be used to estimate where and when similar transitions may occur in other rural locations.

\section{CONCLUSION}

We have highlighted the need for resilience thinking to embrace a reflexive orientation in order to improve its analytical utility for the study of social phenomena in SES and its practical applications. The role of human agency is critical to understanding system resilience. The capacity of individuals to make sense of change and to make decisions they believe are best for them will lead to variable behaviors and unexpected outcomes. There is also the need to acknowledge the multiple interpretations of a social context or phenomenon and that the influence and agendas of those in positions of power will often dominate discourse, and change processes and the outcomes of interventions. Failure to engage critically with discourse could inadvertently privilege dominant power relationships.

Our findings suggest that there is opportunity for resilience thinking to be complemented by other theoretical lenses and approaches to promote reflection on the inevitable limitations 
that each contextual use of resilience thinking involves. We propose that the utility of resilience thinking would be greatly improved if it is applied reflexively; in other words, it is used as an analytical lens, but its assumptions are politicized and challenged. We have identified six areas within the resilience thinking framework for reflexive inquiry, and have suggested some questions as a guide for each. The use of empirical material to problematize the resilience thinking framework can produce new insights into social processes, as demonstrated in the three case studies. By engaging more explicitly with constructive theories of meaning, resilience thinking could better observe and respond to the often-subtle social dynamics in complex SES. A critical reflection on multiple perspectives and divergent narratives could indeed be useful in exposing the influence of dominant power structures and in enabling transformation through political processes.

Responses to this article can be read online at: http://www.ecologyandsociety.org/issues/responses. $\mathrm{php/9705}$

\section{LITERATURE CITED}

Allison, H. E., and R. J. Hobbs. 2004. Resilience, adaptive capacity, and the "lock-in trap" of the Western Australian agricultural region. Ecology and Society 9(1):3. http://dx.doi. org/10.5751/ES-00641-090103

Brand, F. S., and K. Jax. 2007. Focusing the meaning(s) of resilience: resilience as a descriptive concept and a boundary object. Ecology and Society 12(1):23. http://dx.doi.org/10.5751/ ES-02029-120123

Bristow, G., and A. Healy. 2014. Regional resilience: an agency perspective. Regional Studies 48(5):923-935. http://dx.doi. org/10.1080/00343404.2013.854879

Brown, K. 2014. Global environmental change I: a social turn for resilience? Progress in Human Geography 38(1):107-117.

Brown, K., and E. Westaway. 2011. Agency, capacity, and resilience to environmental change: lessons from human development, well-being, and disasters. Annual Review of Environment and Resources 36(1):321-342. http://dx.doi. org/10.1146/annurev-environ-052610-092905

Christensen, L., and N. Krogman. 2012. Social thresholds and their translation into social-ecological management practices. Ecology and Society 17(1):5. http://dx.doi.org/10.5751/ES-04499-170105

Coté, M., and A. J. Nightingale. 2012. Resilience thinking meets social theory. Progress in Human Geography 36(4):475-489. http:// dx.doi.org/10.1177/0309132511425708

Coulthard, S. 2012. Can we be both resilient and well, and what choices do people have? Incorporating agency into the resilience debate from a fisheries perspective. Ecology and Society 17(1):4. http://dx.doi.org/10.5751/ES-04483-170104

Cunliffe, A. L. 2004. On becoming a critically reflexive practitioner. Journal of Management Education 28(4):407-426. http://dx.doi.org/10.1177/1052562904264440
Davidson, D. J. 2010. The applicability of the concept of resilience to social systems: some sources of optimism and nagging doubts. Society \& Natural Resources 23(12):1135-1149. http://dx.doi. org/10.1080/08941921003652940

Davidson, D. J. 2013. We still have a long way to go, and a short time to get there: a response to Fikret Berkes and Helen Ross. Society \& Natural Resources 26(1):21-24. http://dx.doi. org/10.1080/08941920.2012.749758

Davidson, J. L., C. Jacobson, A. Lyth, A. Dedekorkut-Howes, C. L. Baldwin, J. C. Ellison, N. J. Holbrook, M. J. Howes, S. SerraoNeumann, L. Singh-Peterson, and T. F. Smith. 2016. Interrogating resilience: toward a typology to improve its operationalization. Ecology and Society 21(2):27. http://dx.doi. org/10.5751/ES-08450-210227

Davoudi, S. 2012. Resilience: a bridging concept or a dead end? Planning Theory \& Practice 13(2):299-307.

Fabinyi, M., L. Evans, and S. J. Foale. 2014. Social-ecological systems, social diversity, and power: insights from anthropology and political ecology. Ecology and Society 19(4):28. http://dx.doi. org/10.5751/ES-07029-190428

Fath, B. D., C. A. Dean, and H. Katzmair. 2015. Navigating the adaptive cycle: an approach to managing resilience of social systems. Ecology and Society 20(2):24. http://dx.doi.org/10.5751/ ES-07467-200224

Folke, C. 2006. Resilience: the emergence of a perspective for social-ecological systems analyses. Global Environmental Change 16(3):253-267. http://dx.doi.org/10.1016/j.gloenvcha.2006.04.002

Folke, C. 2016. Resilience (republished). Ecology and Society 21 (4):44. http://dx.doi.org/10.5751/ES-09088-210444

Folke, C., S. R. Carpenter, B. Walker, M. Scheffer, T. Chapin, and J. Rockstrom. 2010. Resilience thinking: integrating resilience, adaptability and transformability. Ecology and Society 15(4):20. http://dx.doi.org/10.5751/ES-03610-150420

Groth, T. M., and A. Curtis. 2017. Mapping farmer identity: why, how, and what does it tells us? Australian Geographer 48(3):365383. http://dx.doi.org/10.1080/00049182.2016.1265881

Gunderson, L., and C. Holling. 2002. Panarchy: understanding transformations in human and natural systems. Island Press, Washington, D.C., USA.

Hahn, T., and B. Nykvist. 2017. Are adaptions self-organized, autonomous, and harmonious? Assessing the social-ecological resilience literature. Ecology and Society 22(1):12. http://dx.doi. org/10.5751/ES-09026-220112

Hatt, K. 2013. Social attractors: a proposal to enhance "resilience thinking" about the social. Society \& Natural Resources 26(1):30 43. http://dx.doi.org/10.1080/08941920.2012.695859

Holmes, J. 2006. Impulses towards a multi-functional transition in rural Australia: gaps in the research agenda. Journal of Rural Studies 22:142-160. http://dx.doi.org/10.1016/j.jrurstud.2005.08.006

Ingalls, M. L., and R. C. Stedman. 2016. The power problematic: exploring the uncertain terrains of political ecology and the resilience framework. Ecology and Society 21(1):6. http://dx.doi. org/10.5751/ES-08124-210106 
Kincheloe, J. L. 2005. On to the next level: continuing the conceptualization of the bricolage. Qualitative Inquiry 11(3):323350. http://dx.doi.org/10.1177/1077800405275056

Kirchhoff, T., F. S. Brand, D. Hoheisel, and V. Grimm. 2010. The one-sidedness and cultural bias of the resilience approach. GAIA: Ecological Perspectives for Science \& Society 19(1):25-32. http:// dx.doi.org/10.14512/gaia.19.1.6

Kuhlicke, C. 2013. Resilience: a capacity and a myth: findings from an in-depth case study in disaster management research. Natural Hazards 67(1):61-76. http://dx.doi.org/10.1007/s11069-010-9646y

Kumar, S. 2016. Choosing boundaries for interventions: a study of environmental water in the Murray-Darling Basin, Australia? Dissertation. Charles Sturt University, Sydney, Australia.

Lockwood, M., M. Mitchell, S. A. Moore, and S. Clement. 2014. Biodiversity governance and social-ecological system dynamics: transformation in the Australian Alps. Ecology and Society 19 (2):13. http://dx.doi.org/10.5751/ES-06393-190213

Lynch, M. 2000. Against reflexivity as an academic virtue and source of privileged knowledge. Theory, Culture \& Society 17 (3):26-54. http://dx.doi.org/10.1177/02632760022051202

Lyon, C., and J. R. Parkins. 2013. Toward a social theory of resilience: social systems, cultural systems, and collective action in transitioning forest-based communities. Rural Sociology 78 (4):528-549. http://dx.doi.org/10.1111/ruso.12018

Mackinnon, D., and K. D. Derickson. 2013. From resilience to resourcefulness: a critique of resilience policy and activism. Progress in Human Geography 37(2):253-270. http://dx.doi. org/10.1177/0309132512454775

Midgley, G. 2000. Systemic intervention. Springer, USA.

Nelson, D. R., W. N. Adger, and K. Brown. 2007. Adaptation to environmental change: contributions of a resilience framework. Annual Review of Environment and Resources 32(1):395-419. http://dx.doi.org/10.1146/annurev.energy.32.051807.090348

O'Brien, K. 2012. Global environmental change II: from adaption to deliberate transformation. Progress in Human Geography 36 (5):667-676. http://dx.doi.org/10.1177/0309132511425767

Pelling, M., and D. Manuel-Navarrete. 2011. From resilience to transforamtion: the adaptive cycle in two Mexican urban centers. Ecology and Society 16(2):11. http://dx.doi.org/10.5751/ ES-04038-160211

Rawluk, A. 2015. Interpreting regional landscape change: a case study of the Ovens, Victoria, Australia. Dissertation. Charles Sturt University, Sydney, Australia.

Rawluk, A., and A. Curtis 2016. Reconciling contradictory narratives of landscape change using the adaptive cycle: a case study from southeastern Australia. Ecology and Society 21(1):17. http://dx.doi.org/10.5751/ES-08245-210117

Rawluk, A., and A. Curtis. 2017. "A mirror and a lamp": the role of power in the rural landscape trajectory of the Ovens region of Australia. Society \& Natural Resources 30(8):949-963. http://dx. doi.org/10.1080/08941920.2016.1264651
Rawluk, A., and A. Godber. 2011. Widening the scope of scenario planning in small communities: a case study use of an alternative method. Ecology and Society 16(1):11. http://dx.doi.org/10.5751/ ES-03852-160111

Sinclair, K. 2014. Transformative change in contemporary Australian agriculture. Dissertation. Charles Sturt University, Sydney, Australia.

Sinclair, K., A. Curtis, E. Mendham, and M. Mitchell. 2014. Can resilience thinking provide useful insights for those examining efforts to transform contemporary agriculture? Agriculture and Human Values 31:371-384.

Strunz, S. 2012. Is conceptual vagueness an asset? Arguments from philosophy of science applied to the concept of resilience. Ecological Economics 76:112-118. http://dx.doi.org/10.1016/j. ecolecon.2012.02.012

Tompkins, E., and N. Adger. 2004. Does adaptive management of natural resources enhance resilience to climate change? Ecology and Society 9(2):10.

Ulrich, W. 1983. Critical heurisitics of social planning: a new approach to practical philosophy. Haupt, Bern.

Walker, B. H., N. Abel, J. M. Anderies, and P. Ryan. 2009. Resilience, adaptability, and transformability in the GoulburnBroken Catchment, Australia. Ecology and Society 14(1):12. http://dx.doi.org/10.5751/ES-02824-140112

Walker, B., and D. Salt. 2006. Resilience thinking: sustaining ecosystems and people in a changing world. Island Press, Washington, D.C., USA.

Walker, B., and D. Salt. 2012. Resilience practice: building capacity to absorb disturbance and maintain function. Island Press, Washington, D.C., USA.

Welsh, M. 2014. Resilience and responsibility: governing uncertainty in a complex world. Geographical Journal 180(1):1526. http://dx.doi.org/10.1111/geoj.12012 